\title{
Iron Uptake by Fungi Isolated from Arcelor Mittal -Annaba- in the Northeast of Algeria
}

http://dx.doi.org/10.1590/1806-9061-2020-1321

\section{-Author(s)}

Bourzama G!,II (iD https://orcid.org/0000-0001-6728-4907 Ouled-Haddar H" (D) https://orcid.org/0000-0002-3880-7550 Marrouche M"I (D) https://orcid.org/0000-0001-9202-2554 Aliouat A $\quad$ (ID) https://orcid.org/0000-0003-4177-9017

Microbiology Laboratory, Department of Biochemistry, Faculty of Sciences, Badji Mokhtar University, Annaba, Algeria

" University of Mohamed Seddik Benyahia, Jijel, Laboratory of Molecular Toxicology, 18000, Jijel, Algeria

III Department of Microbiology and Food Science, Faculty of Sciences, Seddike Benyhia University, Jijel, Algeria.

\section{Mail Address}

Corresponding author e-mail address Ghania Bourzama

Department of Biochemistry, Faculty of Sciences, Badji Mokhtar University, Annaba, Algeria.

Phone: 213784303342

Email: gbourzama@yahoo.fr

\section{- Keywords}

Fungi, Iron, screening, toxic, uptake.

\section{ABSTRACT}

The Metal pollution is one of the major risks in the world nowadays. Iron is an essential metal for growth and proliferation of a vast majority of organisms, but it can be toxic to human health and other living beings in the environment at high concentrations due to its increased industrial activity. Fungi have a remarkable capacity to uptake and detoxify iron metal using different mechanisms such as bioaccumulation. Thus, the aim of this work is to study the ability of iron uptake by the fungal strains isolated from Arcelor Mittal -Annaba- in Algeria. Three strains were screened at high concentration of iron $(1 \mathrm{~g} / \mathrm{l})$ and their capacity to uptake iron has been studied on Czapek Yeast Agar medium. The amounts of uptaken iron ions were estimated in the same liquid medium using Atomic Absorption Spectroscopy (AAS). The results of the iron uptake by these screened strains showed that Cladosporium cladosporioides uptakes the highest concentration of iron (347.7 ppm), Aspergillus niger was able to accumulate up to $170 \mathrm{ppm}$ of this metal while, the lowest uptake of this metal was shown by Penicillium citrinum with $106.43 \mathrm{ppm}$. It was found that the spore germination of three fungal strains was low when the medium is supplemented with high concentrations of iron. This indicated the potential of these fungal strains as biological agents for removal of iron from the industrial effluents containing high concentrations of it.

\section{INTRODUCTION}

Iron is an essential metal for growth and proliferation of a vast majority of microorganisms. This essentiality derives from the importance of iron in its biochemically accessible valence status that plays a role in a wide variety of electron transfer processes and enzymatic activities (Kosman, 2003). However, it could be toxic to human health and other living beings in the environment at high concentrations.

The presence of this metal in waste stream ground and drinking water is a very serious concern since the ions of this metal are toxic to various life forms (Wasiu et al., 2016). However, the heavy metals and other constituents leach into the soil and damage the flora and fauna on Earth (Gayatri et al., 2017). The use of microorganisms for decontaminating the environment encumbered with heavy metal pollutants through biosorption is considered as a good option for bioremediation.

Recent developments in the field of environmental biotechnology include the search for microorganisms as potent sorbents for heavy metals. Fungi can tolerate and detoxify metals in various ways. Many mechanisms are used by fungal strains to eliminate metals, in instance adsorption, precipitation, enzymatic conversion, active intracellular metal uptake, and mainly biosorption (Ramírez Calderón et al., 2020). Biosorption is a process of metal uptake conducted by either living or 
Bourzama G, Ouled-Haddar H, Marrouche M, Aliouat A
Iron Uptake by Fungi Isolated from Arcelor Mittal -Annaba- in the Northeast of Algeria dead biomass through the binding of metal ions on the cell wall and extracellular materials (Bishnoi \& Garima, 2005). The natural screening of fungal strains may provide a fast and natural source for metal removal. Fe is known as the most environmental pollutant that is frequently produced from human and industrial activities. Thus, in this study, we aim to search for fungal strains that are able to eliminate the iron metal under laboratorial conditions.

\section{MATERIAL AND METHODS}

\section{Isolation and identification of the fungal strains}

Isolation and purification of the fungal strains from soil of Arcelor Mittal, in Annaba / Algeria (with 7.8 mg. $\mathrm{Kg}^{-1}$ of iron) were performed on PDA (Potatoes Dextrose Agar) at $25^{\circ} \mathrm{C}$ for 7 days (Pochon \& Tardieux, 1962).

The identification was carried out based on the macroscopic and microscopic characters (Harrigan \& McCance, 1976; Oteng-Gyang, 1984; Botton et al., 1999). To obtain pure cultures, the isolates were subcultured on PDA at $25^{\circ} \mathrm{C}$ for 7 days and preserved at $4^{\circ} \mathrm{C}$. These pure cultures served as a source of inoculums to be used in the assays of screening, uptake and fungal sporulation.

\section{Screening of iron resistant fungal strains}

This experiment identifies the most effective strains that have the ability to grow on PDA medium containing high concentrations of iron $\left(\mathrm{FeSO}_{4}, 7 \mathrm{H}_{2} \mathrm{O}\right)$. Petri dishes were inoculated and the cultures were incubated at $25^{\circ} \mathrm{C}$ for one week. The diameters of the radial growth of these fungi were measured and compared with the control plates (without Fe) (Anahid et al., 2011; Levinskaité et al., 2009).

\section{Effect of iron concentrations on fungal sporulation}

To counting the spores of the screened strains, a series of dilutions $\left(10^{-1}-10^{-5}\right)$ was performed from the spore solution of the screened strains. The amount of spores in the dilution $10^{-5}$ was counted on Malassez cell under optical microscopy (objective x100) (Hopwood et al., 1985). The relationship used for calculation is as follows (Solis-Pereira et al., 1993):

$$
\mathrm{N}=\mathrm{n} \cdot 10^{5} \cdot \mathrm{F}
$$

Where $\mathrm{N}$ is the number of spores per $\mathrm{ml}$ initial suspension, $\mathrm{n}$ is the medium number of spores in the counting cell and $\mathrm{F}$ is the dilution factor.
The results were expressed with the number of spores per $\mathrm{ml}$ of the initial suspension.

\section{Iron uptake by the screened fungal strains}

The screened fungal strains which showed the maximum capacity towards iron were further used for this study according to Levinskaité et al., (2009). Two $\mathrm{ml}$ from the fungal suspension with $10^{6} / \mathrm{ml}$ of the screened strains was transferred to each tube containing different concentrations of Fe $(2000,3000$, $40006000,8000,10000,12000$ and 14000 ppm). The tube that contains the same components except iron was used as a control. The cultures were incubated on a rotary shaker at $25 \pm 2^{\circ} \mathrm{C}$ for one week (Levinskaité et al., 2009). After incubation time, fungal biomass was collected by centrifugation at $9000 \mathrm{rpm}$ for 20 min. The pellet thus obtained was washed three times with normal saline, dried at $105{ }^{\circ} \mathrm{C}$ for 3 hours and weighed.

The dry biomass of each strain (150 mg) was introduced into digestion vessels with $0.9 \mathrm{ml}$ of nitric acid $\left(\mathrm{HNO}_{3}\right)$ and $2.7 \mathrm{ml}$ of hydrochloric acid $(\mathrm{HCL})$. After the digestion period (30 min), the containers were cooled to room temperature (about $30 \mathrm{~min}$ ) and the solution volumes were supplemented up to $15 \mathrm{ml}$ for each sample with deionized water and analyzed using atomic absorption spectroscopy (AAS) "AA6200 SHIMADZU".

\section{RESULTS AND DISCUSSION}

\section{Screening of iron tolerant strains}

Three isolated strains: Cladosporium cladosporioides, Penicillium citrinum and Aspergillus niger were able to continue their growth in presence of high concentrations of iron in the laboratory (Fig. 1), this may be in agreement with the results of Gorbunova and Terekhova (1995), who found that $61 \%$ of the moulds are likely to grow on soils affected by ferric wastes. De Groot and Woodward (1999) have shown that the survival of the fungal species in the polluted soils can be related to their extrinsic characteristics, including cell wall composition, extracellular polysaccharides and the elimination of metabolites, leading to the binding or precipitation of metals such as iron (this normally occurs in the soil). Levinskaité et al. (2009) reported in their study that the fungal strains: Aspergillus niger and Penicillium oxalicum were able to tolerate up to $20 \mathrm{mM}$ of iron. Other researchers (Anahid et al., 2011) have demonstrated that the fungal strain Penicillium simplicissimum can tolerate iron up to $2500 \mathrm{ppm}$. The values obtained from their study are lower than ours. 
Bourzama G, Ouled-Haddar H, Marrouche M, Aliouat A

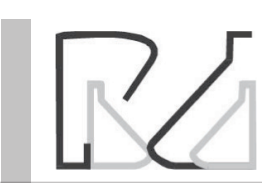

Iron Uptake by Fungi Isolated from Arcelor Mittal -Annaba- in the Northeast of Algeria
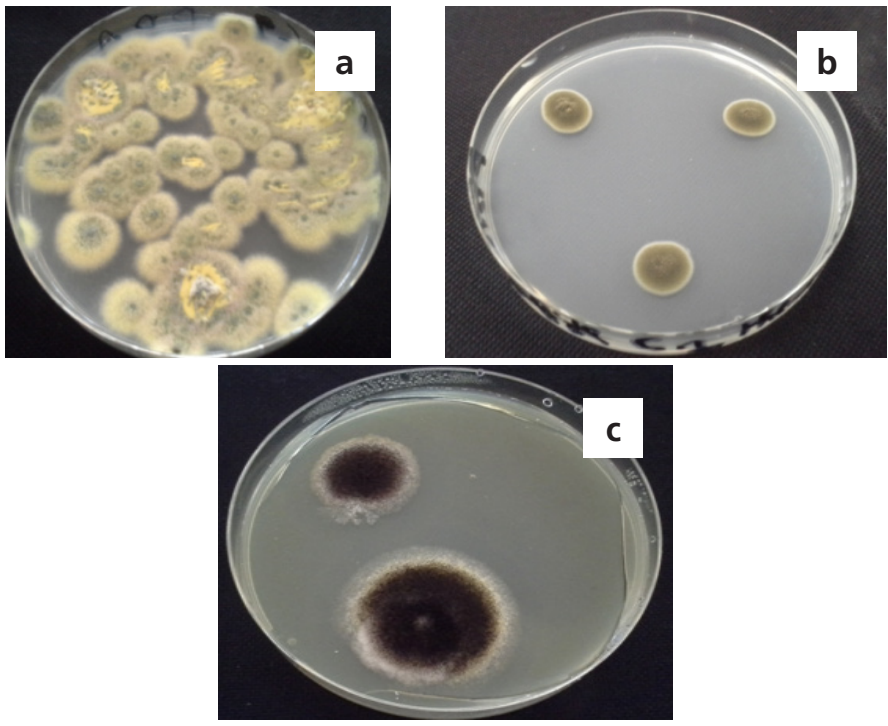

Figure 1 - 7 days-old fungal colonies of the isolated strains on PDA plates with 0 ppm of Fe concentrations: a. Penicillium citrinum, b. Cladosporium cladosporioides, c. Aspergillus niger

\section{Effect of iron concentrations on fungal sporulation}

This test allowed us to study the germination of the selected fungal strains in absence and in presence of different iron concentrations (Fig. 2).

The obtained results are consistent with the results of Wazeer and colleagues (2014) who studied the effect of heavy metals on the germination of Isaria javanica strain isolated from the soil and found that the spore germination was low when the medium is supplemented with iron. However, this result affirmed the used of screened strains in their vegetative form.
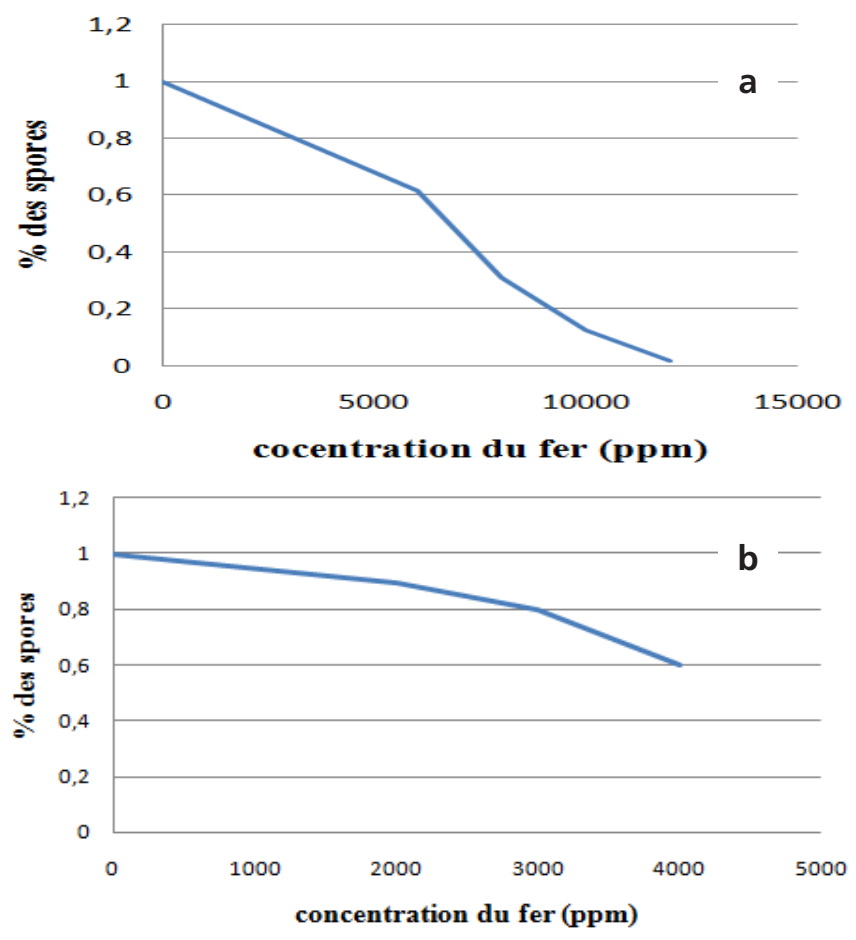

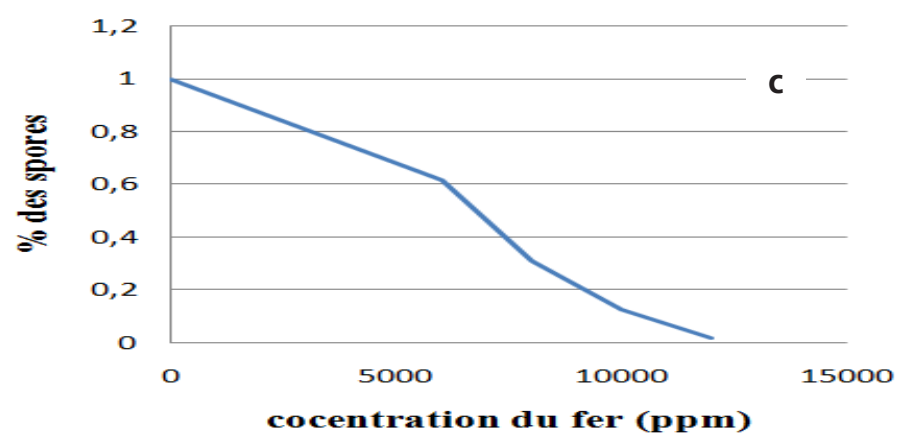

Figure 2 - Variation of fungal sporulation rate with iron concentration: a. Cladosporium cladosporioides, b. Penicillium citrinum, c. Aspergillus niger.

\section{Iron uptake by the isolated fungal strains}

This test studies the process of iron bioaccumulation by the three selected strains: Cladosporium cladosporioides, Penicillium citrinum and Aspergillus niger in absence and in presence of different initial concentrations of iron, the objective to assess the most effective accumulation capacity among them. The values obtained are expressed in ppm as shown in Figure 3.

The results of Levinskaité and his collaborators (2009) are in agreement with ours, they noted that the fungal strain Penicillium oxalicum is capable of accumulating up to $94.8 \%$ iron present in the medium, this high accumulation capacity means that $1 \mathrm{mM}$ of iron added previously to the medium has no negative effect on the growth of the fungal biomass, this value is lower than ours due to the type of medium, the type of mould (species) and the range of the used iron concentrations.
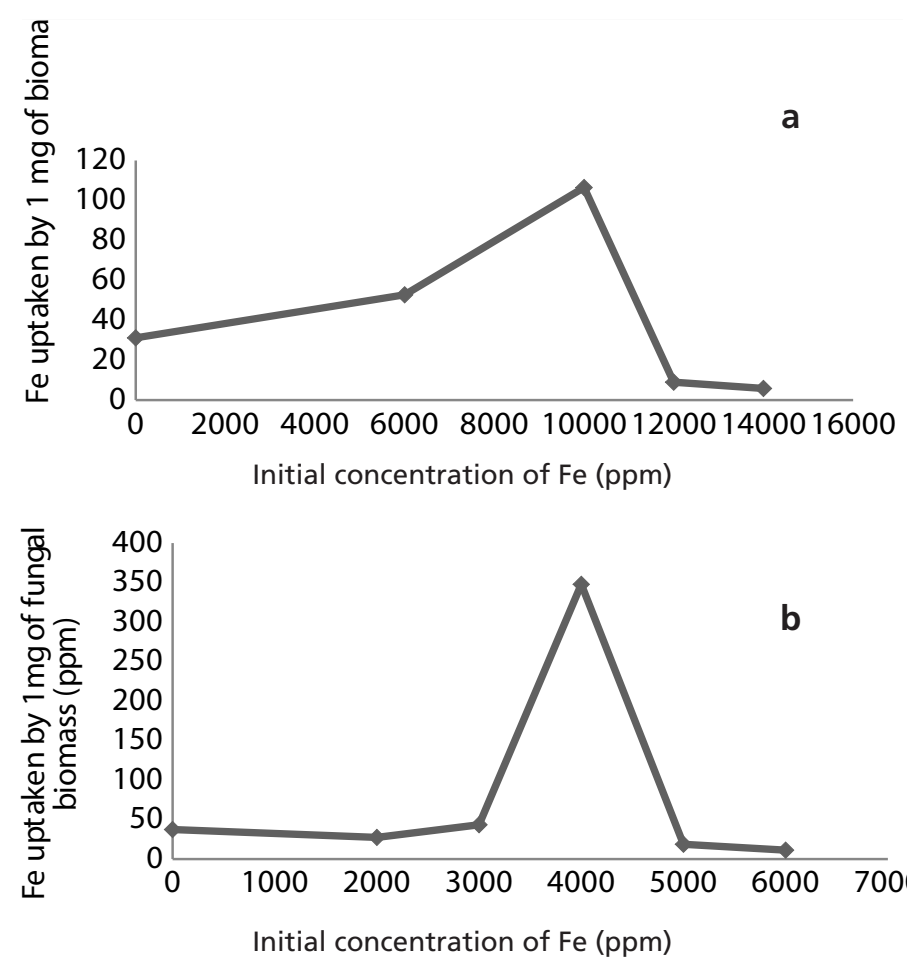
Bourzama G, Ouled-Haddar H, Marrouche M, Aliouat A

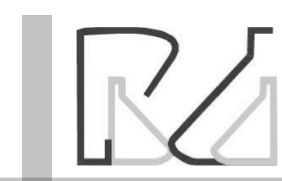

Iron Uptake by Fungi Isolated from Arcelor Mittal

-Annaba- in the Northeast of Algeria

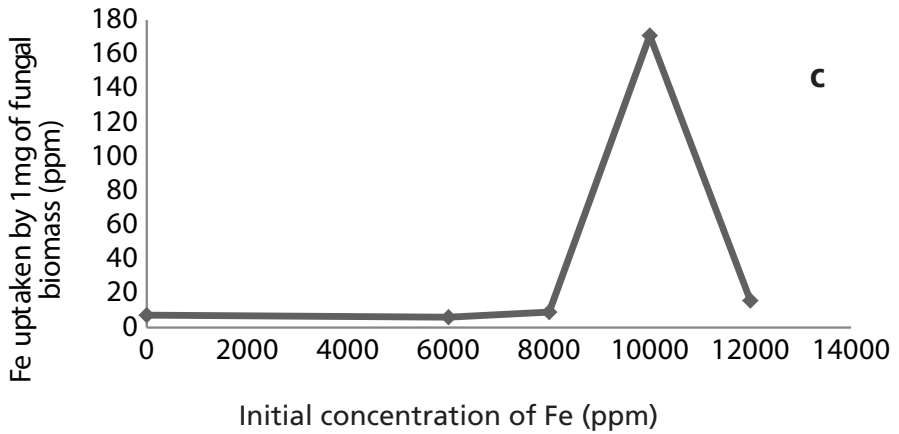

Figure 3 -Amounts of the uptaken Iron (Fe) by the screened fungal strains: a. Penicillium citrinum, b. Cladosporium cladosporioides, c. Aspergillus niger.

\section{CONCLUSION}

In this study, we isolated and screened three fungal strains that are able to uptake iron ions. It was found that the spore germination was low when the medium is supplemented with iron. It could retain relatively high quantities of iron derivatives with increased capacity towards the adsorption of the amending metal ion, although its specific mechanisms of the removal metal have not been completely clarified. These results indicate the potential applicability of these fungi for the remediation of heavy metals from polluted soils and water. Therefore, this study offers new agents for eco-friendly elimination of heavy metal from the environment.

\section{CONFLICTS OF INTEREST}

The authors hereby declare that we do not have any conflict of interest in regard to the information provided in this study.

\section{REFERENCES}

Anahid S, Yaghmaei S, Ghobadinejad Z. Heavy metal tolerance of fungi. Scientia Iranica 2011;18:502-508.

Bishnoi N, Garima R. Fungus-an alternative for bioremediation of heavy metal containing wastewater: a review. Journal of Scientific and Industrial Research 2005;64 (2):93-100.

Botton B, Breton A, Fevre M, Gauthierm S, Guy P, Larpent JP, et al. Moisissures utiles et nuisibles. Importance industrielle. Masson; 1999. p. 12-426.
De Groot RC, Woodward B. Using copper-tolerant fungi to biodegrade wood treated with copper-based preservatives. International Biodeterioration and Biodegradation 1999;44:17-27.

Gayatri Y, Shailaja RM, Vijayalakshmi B. Biosorption of lead by Bacillus licheniformis isolated from e-waste landfill, Hyderabad, Telangana, India. International Journal of Bioassays 2017;6(2):5240-5244.

Gorbunova EA, Terekhova BA. Heavy metals as a stress factor towards fungi manifestation of their action on the cell and organism level. Mycology and Phytopathology 1995;29:63-69.

Harrigan WF, McCance ME. Laboratory methods in food and dairy microbiology. London: Academic Press; 1995. p.21-277.

Hopwood DA, Bibb MJ, Chater KF, Kieser T, Bruton CJ, Kieser HM, et al. Genetic manipulation of streptomyces: a laboratory manual. Norwich: John Innes Foundation; 1985.

Kosman DJ. Molecular mechanisms of iron uptake in fungi. Molecular Microbiology 2003;47(5):1185-1197.

Levinskaite L, Smirnov A, Luksiene B, Druteikiene R, Remeikis V, Baltrunas D. Pu (IV) and Fe (III) accumulation ability of heavy metal- tolerant soil fungi. Nukleonika 2009;54:285-290.

Oteng-Gyang K. Introduction à la microbiologie alimentaire dans les pays chaud. Paris: Lavoisier; 1984. p.26-42.

Pochon J, Tradieux P. Techniques d'analyse en microbiologie du sol. St Mandré: Edition de la Tourelle; 1962. p.110-111.

Rafal O, Agnieszka L, Wojciech P, Anna M, Paulina, M. Characteristics and taxonomy of Cladosporium fungi. Mikologia lekarska 2012;19:(2), 80 85.

Ramírez Calderón OA, Abdeldayem OM, Pugazhendhi A. Current updates and perspectives of biosorption technology: an alternative for the removal of heavymetals from wastewater. Current Pollution Reports 2020;6:8-27

Solis-Pereira S, Ernesto FT, Gustero VG, Mariano-Gutierrez R. Effect of different carbon sources on the synthesis of pectinase by Aspergillus niger in submerged and solid state fermentation. Applied Microbiology and Biotechnology 1993;39:36-41.

Wasiu MO, Oladotum E, Tumbosun I, Oluremi O, Ogundele K, Temitope F. Heavy metal contamination in stream water and sediments of gold mining area of SouthWestern Nigeria'. African Journal of Environmental Science and Technology 2016;10(5):150-161.

Wazeer A, Lazgen $H$, Mohammad Sidqi M. Effect of heavy metal ions on the growth, sporulation and pathogenicty of Isaria Javanica = (Paecilomyces Javanicus). International Journal of Pure and Applied Sciences and Technology 2014;20(2):1-7. 